\title{
CARACTERIZAÇÃO DA COMUNIDADE FITOPLANCTÔNICA, COM ÊNFASE EM CIANOBACTÉRIAS, DO PARQUE ECOLÓGICO DO BAGUAÇU, ARAÇATUBA-SP
}

\author{
Heloísa Gioli Sertório
}

Germano Henrique Costa Barrilli

Natalia Felix Negreiros

RESUMO: A comunidade de algas planctônicas contribuem na produção de matéria orgânica e na oxigenação do ambiente. As cianobactérias apresentam capacidade adaptativa em diversos ambientes e o processo de eutrofização nos corpos d'água desencadeia seu desenvolvimento exacerbado. $O$ presente trabalho objetivou fazer à identificação e a quantificação da comunidade fitoplanctônica, com ênfase em cianobactérias, no lago do Parque Ecológico do Baguaçu, no município de Araçatuba-SP, avaliando a composição, abundância e diversidade e correlacionando estes aos fatores físicos, químicos e biológicos. Foram identificados 41 táxons, distribuídos em 7 classes. $\mathrm{A}$ classe Cyanophyceae apresentou o maior número de táxons (14), seguido pela Chlorophyceae com 12 táxons, Bacillariophyceae com 10 táxons, Zygnemaphyceae com 2 táxons e as classes Euglenophyceae, Chryptophyceae e Dinophyceae com apenas 1 táxon cada. A análise da comunidade fitoplanctônica revelou um padrão diferenciado na abundância e diversidade de espécies apresentando um papel ecológico muito importante em corpos d'água eutróficos, pela capacidade de formarem densos florescimentos ("blooms") com elevada toxicidade. Mesmo em baixas densidades algumas delas requerem a atenção necessária do ponto de vista sanitário, exigindo monitoramento contínuo, pois a possível produção de toxinas pode acarretar consequências adversas à saúde do homem e dos animais.

Palavras-chaves: Cianobactérias; Ribeirão Baguaçu; Abastecimento público de Araçatuba. 


\section{INTRODUÇÃO}

O fitoplâncton é constituído por diversos grupos taxonômicos que possuem necessidades fisiológicas diferentes e respondem de modo distinto às variáveis físicas e químicas como, luz, temperatura e nutrientes nos ambientes aquáticos (CALIJURI et al., 2006), são compostos por organismos que são capazes de realizar fotossíntese. No ambiente aquático, há um maior desenvolvimento das populações fitoplanctônicas em águas lênticas e rios maiores com menor velocidade de corrente (WETZEL, 1975). O desenvolvimento industrial, o crescimento urbano e a expansão de áreas agriculturáveis levam ao aumento destes nutrientes essenciais (processo de eutrofização) para o fitoplâncton e macrófitas aquáticas (CALIJURI et al., 2006).

O processo de eutrofização provocada aumento da biomassa; alterações na diversidade de espécies; diminuição da concentração de oxigênio dissolvido na água; diminuição da transparência da água; mortandade de peixes; aumento de concentrações iônicas; aumento da condutividade elétrica da água; acúmulo de fósforo no sedimento; produção de odores desagradáveis na água devido à decomposição de organismos; mudanças de $\mathrm{pH}$; florações de cianobactérias e produção de toxinas (CALIJURI et al., 2006). Em decorrência de possuírem características fisiológicas e morfológicas viáveis as cianobactérias são organismos que apresentam grande capacidade adaptativa em diversos ambientes sendo necessário ter um ótimo controle ambiental (CALIJURI et al.,2006).

\section{DESENVOLVIMENTO}

O município de Araçatuba possui, segundo o IBGE de 2010 aproximadamente 180 mil habitantes e está localizado na região noroeste do Estado de São Paulo. O Parque Ecológico do Baguaçu (PEBA) encontra-se na latitude 21013'07".5 sul e longitude 50²5'37".5 oeste (ARAÇATUBA, 1978), cortado pelo Ribeirão Baguaçu, que abastece $70 \%$ da cidade de Araçatuba. O PEBA está dentro do perímetro urbano de Araçatuba-SP e corresponde a uma reserva ecológica de visitação pública. Na sua fauna, destacam-se as capivaras (Figura 1A) que vivem próximas a uma lagoa. Esta apresenta uma 
profundidade média estimada na faixa de 3,5 a 5,0 metros, com presença de macrófitas aquáticas, com dominância de Pistia stratiotes, popularmente conhecida como alface d'água (Figura 1B).
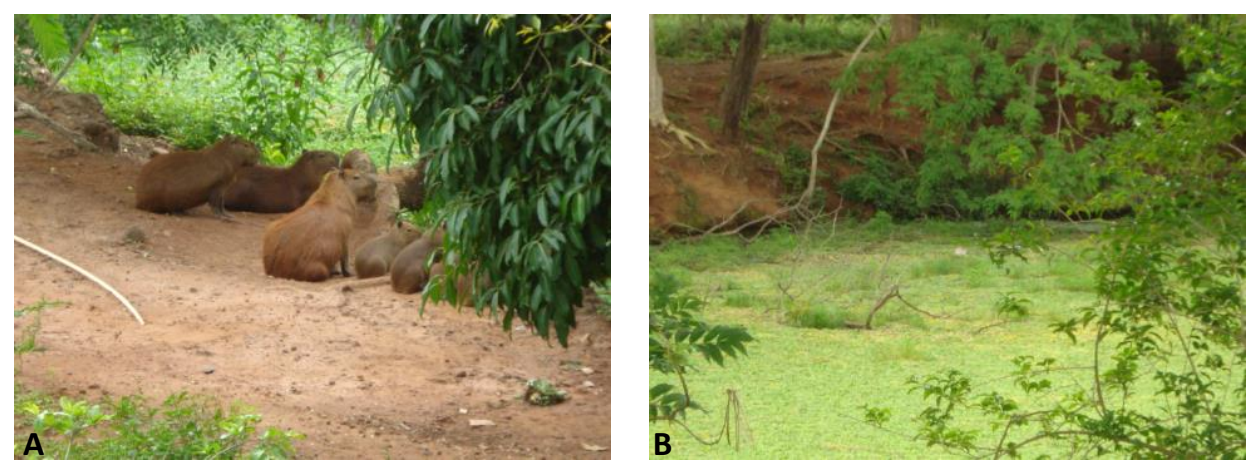

Figura 1. A: Família de capivaras, vivendo próximo ao Lago do Parque Ecológico do Baguaçu, B: Vista do lago, recoberto por macrófitas aquáticas e algas planctônicas, localizado no município de Araçatuba-SP.

As coletas foram realizadas em um ponto próximo á margem na superfície do lago, em três períodos sazonais do ano: primavera, verão e outono.

\subsection{MATERIAL E MÉTODOS}

As variáveis climatológicas foram obtidas junto às estações meteorológicas do município de Araçatuba, na estação de Votuporanga no período em que as coletas foram realizadas.

A temperatura da água foi mensurada com termômetro de mercúrio, a condutividade elétrica foi feita por um condutivímetro digital, o $\mathrm{pH}$ foi aferido por meio do pHmetro digital e a concentração de oxigênio dissolvido através de um oxímetro digital. A transparência da água foi determinada através da realização de leituras do desaparecimento e reaparecimento visual do disco de Secchi (MARGALEF, 1983).

A concentração do material em suspensão foi determinada segundo o método gravimétrico descrito em Teixeira et al. (1965). Para a determinação da concentração de clorofila a foi utilizado o método de extração e cálculo descrito em Golterman et al. (1978). Foi calculado o índice de Estado Trófico (IET) de Lamparelli, modificado pela Cetesb. 
As amostras de água foram fixadas com formol na concentração final de 4\%. Para a contagem de células e organismos fitoplanctônicos foi utilizado o método de Utermohl, usando um microscópio invertido (Zeiss Axiovert). Foram utilizadas câmaras de sedimentação que variaram de 15 a $100 \mathrm{~mL}$, com tempo de sedimentação de três horas para cada centímetro de altura da câmara (MARGALEF,1983). Para a identificação das espécies fitoplanctônicas foi realizada segundo as características morfológicas e morfométricas dos mesmos, com base em bibliografia específica.

A Análise de Componentes Principais (PCA) foi aplicada para comparar a distribuição dos parâmetros ambientais, tais como os parâmetros das variáveis físicas, químicas e da variável biológica concentração de clorofila a nos locais de amostragem, no lago do "PEBA". A Análise de Correspondência Canônica (CCA) foi aplicada para verificar a existência de correspondências entre os parâmetros ambientais e a densidade das classes fitoplanctônicas. Para verificar o nível de significância dos parâmetros ambientais e a densidade das classes fitoplanctônicas, foi aplicado o Teste de Monte Carlo, com 999 permutações randômicas, com valor de $p$ menor ou igual a $0,5(p \leq 0,5)$, realizadas pelo programa CANOCO 3.12 (TER BRAAK \& ŠMILAUER 2002).

\section{RESULTADOS E DISCUSSÕES}

Segundo INFANTE (1988), a distribuição de fatores físicos e químicos é responsável pelo desenvolvimento e estabelecimento das comunidades, uma vez que essas variáveis alteram as condições do sistema através dos movimentos da massa de água, gases e nutrientes. Entre esses fatores controladores da dinâmica nos lagos, podem ser destacados a ação dos ventos, chuvas, variação da temperatura, influência humana e animal. A tabela 1 refere-se a dados meteorológicos obtidos na estação meteorológica de Votuporanga no dia das coletas. 
Tabela 1: Dados meteorológicos.

\begin{tabular}{ccccc}
\cline { 2 - 4 } & Parâmetros & Primavera & Verão & Outono \\
\cline { 2 - 5 } & & & \\
& Velocidade do vento $(\mathrm{m} / \mathrm{s})$ & 6,25 & 7,35 & 5,65 \\
& $\begin{array}{c}\text { Temperatura do } \operatorname{ar}\left({ }^{\circ} \mathrm{C}\right) \\
\text { Umidade relativa do ar }(\%) \\
\text { Precipitação acumulada } \\
(\mathrm{mm})\end{array}$ & 60,5 & 100 & 54 \\
Fonte: Ceptec/INPE. & 250 & 0 & 0,75 \\
\cline { 2 - 5 } & & & 26,5 &
\end{tabular}

Os registros de ocorrência e intensidade dos ventos no lago do PEBA avaliados no presente estudo demonstram que houve influência permanente de ventos e de sua maior intensidade no verão $(7,35 \mathrm{~m} / \mathrm{s})$, seguido pela primavera $(6,25 \mathrm{~m} / \mathrm{s})$ e de menor intensidade no outono $(5,65 \mathrm{~m} / \mathrm{s})$.

Os valores da temperatura do ar registrados no estudo mantiveram uma tendência sazonal, com o maior valor registrado no outono e os menores valores nos períodos de primavera e verão. Índices elevados de precipitação pluviométrica desencadeiam uma série de processos que afetam as condições físicas e químicas de um sistema (ZANATA, 1999). A partir da análise dos dados de precipitação obtidos na estação meteorológica de Votuporanga referenciada durante o estudo, verificou-se uma variação sazonal climática na região estudada com tendência de chuvas durante os meses de verão (mesmo com a precipitação acumulada tendo valor zero no dia da coleta, porém, nos dias anteriormente, a precipitação variou de 225 a $250 \mathrm{~mm}$ ) e redução destes valores no outono, logo, o período de maior profundidade $(45 \mathrm{~cm})$ no lago foi observado no verão. Algumas pequenas variações registradas durante o período deste estudo estiveram dentro dos valores médios para uma série histórica de dados meteorológicos na região, estando próximos aos reportados por Santos (2010).

Os fatores abióticos podem interferir na densidade das populações planctônicas alterando as interações bióticas dentro do sistema (ESPÍNDOLA, 1994). Diversos estudos têm demonstrado a influência de fatores ambientais como condições climáticas, pH, condutividade, temperatura, oxigênio dissolvido, disponibilidade de nutrientes sobre os organismos das comunidades tanto fitoplanctônica como zooplanctônica (SHAPIRO, 1984; REYNOLDS, 1984; ESPÍNDOLA, 1994; MELÃO, 1999; SANTOS-WISNIEWISKI, 
1998). As variáveis físicas e químicas determinadas neste estudo são mostradas na Tabela 2, com os valores de média e desvio padrão.

Tabela 2: Variáveis físicas e químicas do Lago do Parque Ecológico Baguaçu (PEBA) $2012 / 2013$.

\begin{tabular}{|c|c|c|c|c|c|}
\hline Parâmetros & Primavera & Verão & Outono & Média & $\begin{array}{l}\text { Desvio } \\
\text { Padrão }\end{array}$ \\
\hline Profundidade $(\mathrm{cm})$ & 30,00 & 45,00 & 37,00 & 37,33 & 7,51 \\
\hline Temperatura da água $\left({ }^{\circ} \mathrm{C}\right)$ & 22,50 & 34,10 & 34,00 & 30,20 & 6,67 \\
\hline $\mathbf{P h}$ & 6,70 & 7,00 & 7,30 & 7,00 & 0,30 \\
\hline Oxigênio dissolvido (mg. $\left.\mathrm{L}^{-1}\right)$ & 5,10 & 8,90 & 3,90 & 5,97 & 2,61 \\
\hline Condutividade elétrica ( $\mu$ S. $\mathrm{cm}^{-1}$ ) & 45,00 & 1,10 & 1,00 & 15,70 & 25,37 \\
\hline Secchi (cm) & 15,00 & 8,00 & 25,00 & 16,00 & 8,54 \\
\hline Clorofila a ( $\mu \mathrm{g} / \mathrm{L})$ & 74,04 & 107,02 & 51,75 & 77,60 & 27,81 \\
\hline Material em suspensão total (mg. $\left.\mathrm{L}^{-1}\right)$ & 0,01 & 0,02 & 0,00 & 0,01 & 0,01 \\
\hline Material orgânico $\left(\mathrm{mg} \cdot \mathrm{L}^{-1}\right)$ & 0,01 & 0,01 & 0,00 & 0,00 & 0,00 \\
\hline Material inorgânico (mg. $\left.\mathrm{L}^{-1}\right)$ & 0,00 & 0,01 & 0,00 & 0,01 & 0,01 \\
\hline Nitrogênio total ( $\mu \mathrm{g} / \mathrm{L})$ & 1612,82 & * & * & * & * \\
\hline Fósforo total $(\mu \mathrm{g} / \mathrm{L})$ & 218,66 & * & * & * & * \\
\hline IET (Cla) $\left(\mathrm{mg} / \mathrm{m}^{3}\right)$ & 71,91 & 73,72 & 70,16 & 71,93 & 1,78 \\
\hline
\end{tabular}

${ }^{*}$ Resultados ainda não aferidos.

A transparência da água encontra-se geralmente relacionada com a quantidade de material na coluna d'água, tanto particulado quanto dissolvido, mantendo uma relação direta com a produção autóctone e com as entradas alóctones que ocorrem no sistema (WETZEL, 1993). Essa relação foi observada no período chuvoso (verão) quando se observou uma menor transparência da água (visibilidade do disco de Secchi) e concentrações mais elevadas de material em suspensão no lago.

A temperatura em sistemas tropicais é importante sob o ponto de vista ecológico pelos efeitos diretos sobre os processos metabólicos e pela sua relação com as estratégias adaptativas das espécies (MELÃO, 1999). Os maiores valores da temperatura da água no presente estudo foram registrados no verão e no outono, atingindo $34^{\circ} \mathrm{C}$ na superfície do lago. A menor temperatura foi registrada na primavera, atingindo $22,5^{\circ} \mathrm{C}$. Tais características também foram observadas no trabalho de Santos (2010). 
As comunidades vegetais, animais e o meio aquático possuem estreita interdependência com o pH pois ele afeta a dinâmica dos sistemas aquáticos. De maneira geral, o pH do presente estudo variou ligeiramente de pouco ácido a neutro. O maior valor registrado para o pH ocorreu no outono $(7,3)$ e o menor valor registrado, ocorreu na primavera $(6,7)$. Os resultados obtidos para esta variável se enquadram na Resolução n`357 de 2005 do CONAMA, que estabelece valores entre 6,0 e 9,0 para a proteção das comunidades aquáticas.

A concentração de oxigênio dissolvido no presente estudo foi maior no verão, apresentando 8,9mg.L-1 e menor no outono com 3, 9mg.L-1. Os valores registrados de condutividade elétrica no presente estudo foi maior na primavera $(45 \mu \mathrm{S} . \mathrm{cm}-1)$ e sem variações consideradas no verão e no outono. Os resultados relativos às concentrações de material em suspensão total no presente estudo relataram os maiores valores no verão (período chuvoso), assim como reportado por Santos (2010). As concentrações de material em suspensão orgânico e inorgânico também foram de maior valor no verão. Este resultado deve-se pela ocorrência de um maior índice de precipitação pluviométrica registrados no período do verão, com isso houve um maior carreamento de substâncias e consequentemente diminuindo a penetração de luz e extensão da zona eufótica e também pela influência da produção primária, que contribui para elevadas concentrações de matéria orgânica.

Para o desenvolvimento da biota aquática os nutrientes são fundamentais e podem ocasionar, quando em excesso, a alteração do estado trófico, promovendo a eutrofização em ecossistemas aquáticos. Os valores relativos à concentração de nitrogênio e fósforo total foram de 1612,82 e $218,66 \mu \mathrm{g} / \mathrm{L}$, respectivamente. Os valores do índice de estado trófico foram de $71,91 \mathrm{mg} / \mathrm{m}^{3}$ na primavera, $73,72 \mathrm{mg} / \mathrm{m}^{3}$ no verão e $70,16 \mathrm{mg} / \mathrm{m}^{3}$ no outono. Esses valores foram superiores a $69,05 \mathrm{mg} / \mathrm{m}^{3}$ classificando o lago como hipereutrófico.

A porcentagem total explicada pelos dois primeiros componentes na análise de ordenação PCA (Figura 2) foi de 95,8\%. De forma geral, condutividade elétrica foi a variável que provavelmente apresentou a maior influência na amostragem realizada na primavera, já na amostragem realizada no verão, a variável foi clorofila a. As demais 
variáveis estiveram correlacionadas positivamente com a amostragem realizada no outono.

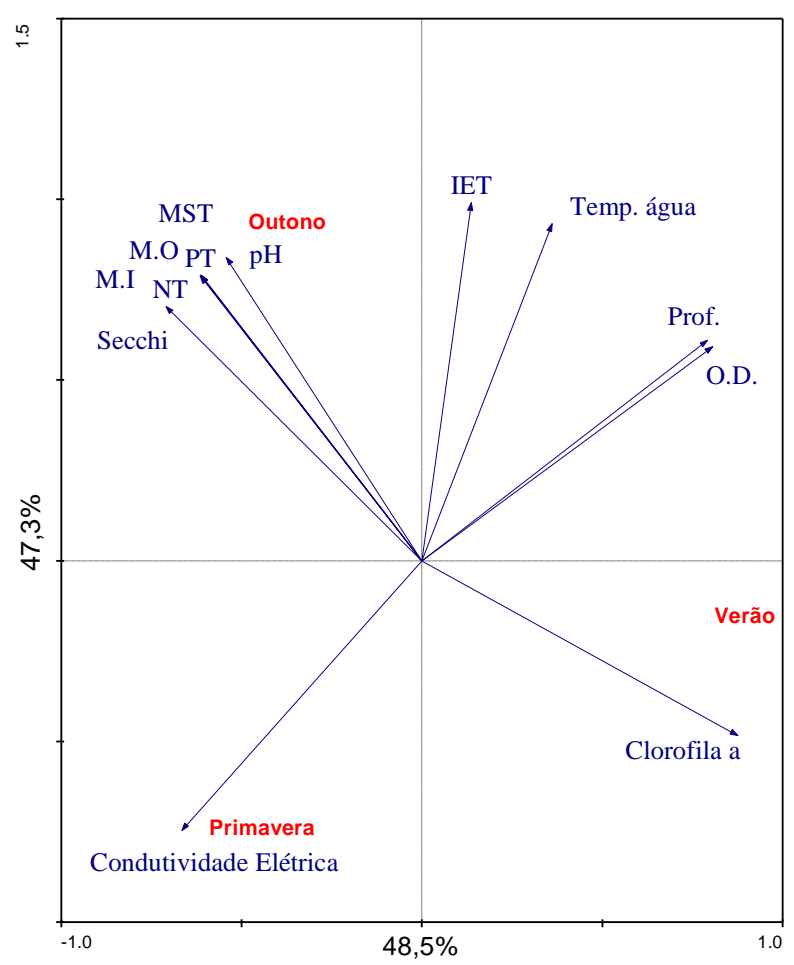

Figura 2: Diagrama de ordenação PCA dos pontos de amostragem realizado no Lago do Parque Ecológico do Baguaçu.

Os valores das concentrações de clorofila a (biomassa algal) evidenciaram que a maior concentração foi no verão - período chuvoso (107,02 $\mu \mathrm{g} / \mathrm{L})$, e a menor foi no outono $(51,75 \mu \mathrm{g} / \mathrm{L})$. Resultado semelhante foi reportado por Santos (2010) em um estudo feito no reservatório de Três Irmãos. Os resultados demonstraram que a alta concentração de clorofila a no verão pode ser devido a variabilidade das populações fitoplanctônicas dominantes (BARBOSA et al., 1999), a toxicidade (FRACACIO, 2001).

A composição do fitoplâncton no Lago do Parque Ecológico do Baguaçu (PEBA) em Araçatuba-SP demonstra uma comunidade de elevada riqueza de espécies, considerando-se que com apenas um ponto amostral no lago, foram identificados 41 táxons, distribuídos em 7 classes. O número de espécies apresenta uma relação direta com a área amostral verificando-se uma tendência de número crescente de espécies com 
o aumento da área estudada, até um máximo onde ocorre a saturação (MAGURRAN, 2004).

Em uma análise temporal das classes taxonômicas registradas no presente estudo, verificou-se que Cyanophyceae (34\%), Chlorophyceae (29\%) e Bacillariophyceae (24\%) foram predominantes nas amostras fitoplanctônicas (Figura 3). Numericamente a classe Cyanophyceae foi dominante sobre as demais, e apresentou também maior riqueza de espécies, quando comparadas aos demais grupos. Santos (2010) registrou resultados similares em seu trabalho.

Figura 3: Composição Taxonômica da Comunidade Fitoplanctônica do Lago do Parque Ecológico do Baguaçu, Araçatuba-SP.

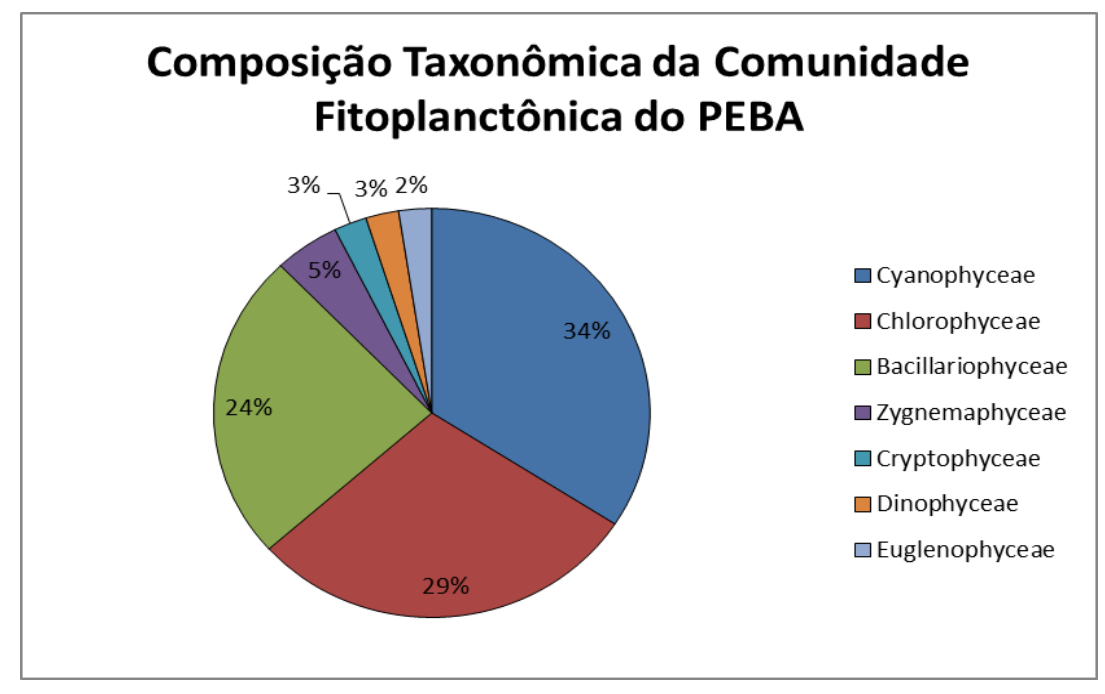

O conhecimento sobre a diversidade da comunidade fitoplanctônica é imprescindível em estudos de avaliação, monitoramento e recuperação de ecossistemas aquáticos, permitindo conhecer as relações entre as variáveis ambientais e a ocorrência de determinados grupos ou espécies sob determinadas condições (STEVENSON \& SMOL, 2003). Mudanças na composição ou no padrão de ocorrência das espécies podem servir de importantes ferramentas aos estudos ecológicos, bem como sanitários, nos corpos de água.

Os táxons da classe Cyanophyceae apresentaram dominância numérica de Merimospedia sp., Aphanocapsa sp., Lyngya sp. e células livres de Microcystis sp. 
Apesar das Chlorophyceae terem apresentado grande riqueza de táxons, estas não atingiram elevada densidade numérica quando comparado com Cyanophyceae. Os representantes da classe Bacillariophyceae ocuparam a terceira posição em relação à riqueza de táxons com destaque principalmente para a espécie mais abundante Pinnularia sp. com maiores densidades no verão.

Figura 4: Densidade da Comunidade Fitoplanctônica do Lago do Parque Ecológico do Baguaçu, Araçatuba-SP.

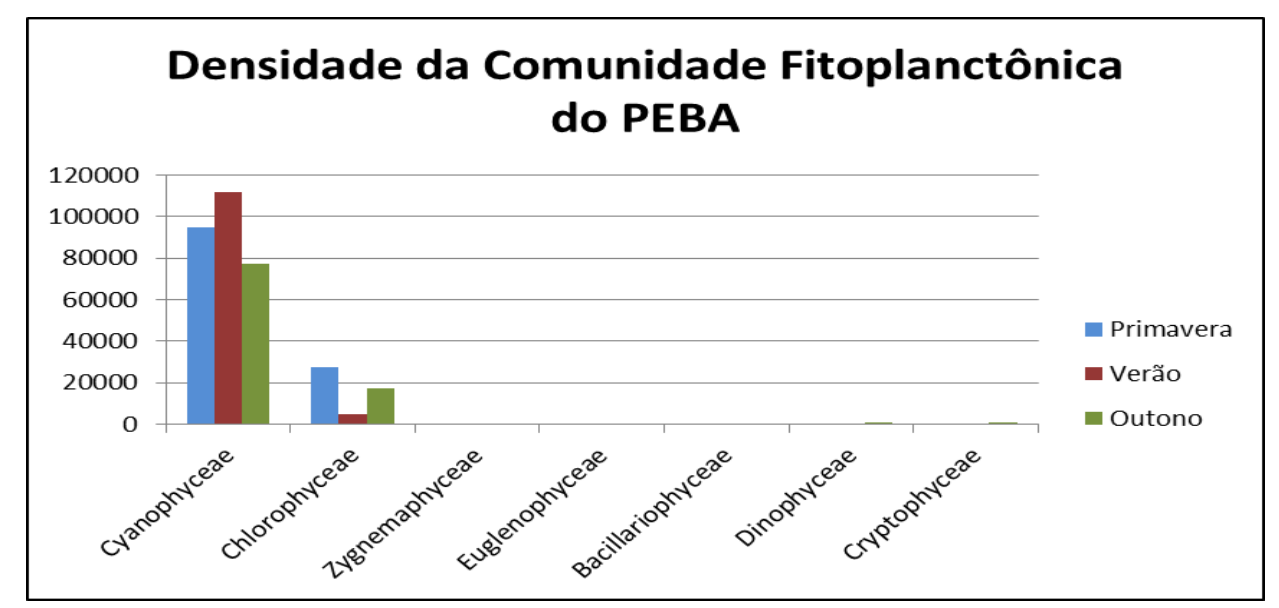

O gráfico demonstra que as espécies mais abundantes de Cyanophyceae ocorreram no verão, às espécies de Chlorophyceae, Euglenophyceae e Bacillariophyceae na primavera e as espécies de Zynemaphyceae, Dinophyceae e Cryptophyceae no outono.

As cianobactérias, principalmente do gênero Microcystis, têm um papel ecológico muito importante em corpos d'água eutróficos, pela sua capacidade de formarem densos florescimentos ("blooms") com elevada toxicidade. No lago estudado ocorreram diversos táxons de cianobactérias que podem possuir linhagens tóxicas, como as espécies dos gêneros Microcystis, Anabaena, Oscillatoria e Lyngbya. Mesmo em baixas densidades algumas delas requerem a atenção necessária do ponto de vista sanitário, exigindo monitoramento contínuo, pois a possível produção de toxinas pode acarretar consequências adversas à saúde do homem e dos animais. Elas também são indicadoras da elevada carga de nutrientes no sistema, principalmente do nitrogênio e fósforo.

Nas amostragens realizadas no presente estudo não foi verificado um padrão regular na ocorrência e densidade dos táxons fitoplanctônicas, com ora um ou outro táxon 
assumindo a dominância. Devido à complexidade dos reservatórios e a dinâmica da comunidade fitoplactônica, as alterações na composição específica do fitoplâncton são muito rápidas (TUNDISI, 1990). Para se conhecer e entender os padrões espaciais e temporais desta comunidade são necessárias coletas mais frequentes, que permitissem acompanhar as rápidas variações em ambas, as condições ambientais e as respostas das espécies fitoplanctônicas.

A análise correspondência de canônica (CCA) evidenciou de forma geral, na amostragem realizada na primavera a condutividade elétrica foi a variável que provavelmente apresentou a maior influência na densidade de Euglenophyceae. Na amostragem realizada no verão a clorofila a, oxigênio dissolvido, IET, material em suspensão total, material orgânico e inorgânico foram as variáveis que provavelmente apresentaram influência na densidade da espécie Bacillarophyceae. Na amostragem realizada no outono a visibilidade do disco de secchi foi a variável que apresentou a maior influência na densidade de Zygnemaphyceae, Dinophyceae, Cryptophyceae e Chlorophyceae.

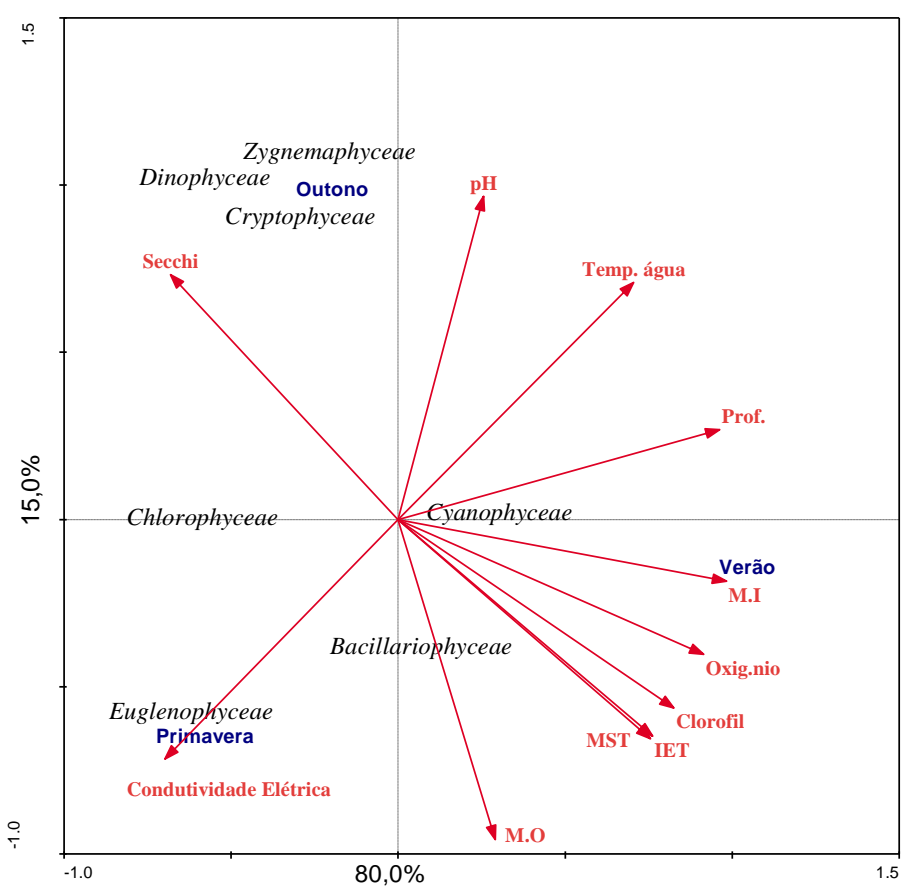

Figura 5: Diagrama de ordenação CCA com base nas densidades (org. $\mathrm{m}^{-3}$ ) das classes fitoplanctônicas e variáveis ambientais, no lago do Peba (MO = concentração de matéria orgânica.IET = Índice de estado trófico). 


\section{Conclusão}

Durante o período de estudo, o Lago do Parque Ecológico do Baguaçu foi caracterizado como ambiente hipereutrófico. Ocorreram variações importantes nas condições físicas e químicas vinculadas aos períodos de primavera e verão acoplados ao regime de chuvas, as quais desencadeiam uma série de mudanças ambientais que acarretaram variações na comunidade planctônica. Embora o fitoplâncton tenha sido constituído por um elevado número de táxons, houve dominância da classe Cyanophyceae, devendo ter uma maior atenção para as espécies dos gêneros Microcystis, Anabaena, Oscillatoria e Lyngbya por serem linhagens tóxicas. Possíveis ações mitigadoras seriam a recuperação da mata ciliar, remoção da família de capivaras que habitam o local no período de recuperação do lago e a interrupção de derramamento de esgoto e entulhos.

\section{REFERÊNCIAS}

ARAÇATUBA. Mapa altimétrico: ano 1978. Araçatuba: Secretaria de Planejamento, Prefeitura Municipal de Araçatuba, 1978.

BARBOSA, F.A.R.; PADISAK, J.; ESPINDOLA, ELG.; BORICS, G.; ROCHA, O. The cascading reservoir continuum concept (CRCC) and its application to the river Tietê-basin, São Paulo State, Brazil. In: TUNDISI, J.G.; STRASKRABA, M. Theoretical reservoir ecology and its applications. São Carlos; Rio de Janeiro, International Institute of ecology, Brazilian Academy of Sciences, 1999, p. 425-437.

CALIJURI, M. C. et al. Cianobactérias e cianotoxinas em águas continetais. Rima Editora, 2006.

ESPÍNDOLA, E.L.G. Dinâmica da associação congenérica das espécies de Notodiaptomus (Copepoda, Calanoida) no reservatório de Barra Bonita, SP. 1994. 
363 f. Tese (Doutorado em Ciências da Engenharia Ambiental) - Centro de Recursos Hídricos e Ecologia Aplicada, Escola de Engenharia de São Carlos, Universidade de São Paulo, São Carlos, 1994.

FRACÁCIO, R., Utilização de bioensaios ecotoxicológcos com Danio rerio (Cypriniforme, Cyprinidae) e análises limnológicas para a avaliação ambiental dos reservatórios do Médio e Baixo Tietê (SP). 2001. 233 f. Dissertação (Mestrado em Ciências da Engenharia Ambiental) - Centro de Recursos Hídricos e Ecologia Aplicada, Escola de Engenharia de São Carlos, Universidade de São Paulo, São Carlos, 2001

GOLTERMAN, H.L.; CLYMO, R.S.; OHNSTAD, M.A.M. Methods for physical and chemical analysis of freshwaters. 2. ed. Oxford: Blackwell Scientific Publications, 1978, 213.

INFANTE, A.G. El plâncton de las águas continentales. Washington: The general secretariat of the organization of American States, 1988, $125 \mathrm{p}$.

MARGALEF, R. Limnologia. Barcelona: Omega, 1983, 1010p.

MAGURRAN, A.E. Measuring Biological Diversity. Inglaterra: Blackwell Publishing, Oxford, 2004, $256 \mathrm{p}$.

MELÃO, M.G.G. Desenvolvimento e aspectos reprodutivos de cladóceros e copépodos de águas continentais brasileiras. In: POMPÊO, M.L.M. (ed.). Perspectivas da limnologia no Brasil. São Luiz: Gráfica e Editora União, 1999, p.45-57.

REYNOLDS, C.S. The ecology of freshwater phytoplankton. 1. ed. Cambridge: Cambridge University Press, 1984, $384 \mathrm{p}$.

SANTOS, R.M. Estrutura das comunidades fitoplanctônicas e zooplanctônicas, com ênfase na produção secundária do zooplâncton, e fatores ambientais relacionados nos reservatórios do baixo Tietê, SP. 2010. Dissertação (Mestrado em Ecologia e 
Recursos Naturais) - Centro de Ciências Biológicas e da Saúde, Universidade Federal de São Carlos, São Carlos, 2010.

SANTOS-WISNIEWSKI, M.J. Distribuição espacial e produção secundária da comunidade zooplanctônica do Reservatório de Barra Bonita - SP. 1998. 240 f. Tese (Doutorado em Ciências) - Centro de Ciências Biológicas e da Saúde, Universidade Federal de São Carlos, São Carlos,1998.

SHAPIRO, J. Blue-green dominance in lakes: the role and management significance of pH and CO2. Int. Revue ges. Hydrobiol., v. 69, n.6, p. 765-780, 1984.

STEVENSON, R.J.; SMOL, J.P. Use of algae in environmental assessments. In: WEHR, J.D.; SHEATH, R.G. Freshwater Algae in North America: classification and ecology San Diego: Academic Press, 2003, p. 775-804.

TEIXEIRA, C.; TUNDISI, J. G. E KUTNER, M. B. Plankton studies in a mangrove. LI: The standing-stock and some ecological factors. Bolm. Inst. Oceonogr., v.24, p.23-41. 1965.

TER BRAAK, C.J.F.; ŠMILAUER, P. Canoco reference manual and CanoDraw for Windows user's guide: software for canonical community ordination. Microcomputer Power, Ithaca, NY, 2002.

TUNDISI, J.G. Conservation and management of continental aquatic ecosystems in Brazil. In: Lake Conservation and Management. HONGLIANG, L.; YUTIAN, W.; HAISHEN, L. (eds.). Proc. 4th Internat. Conf. on the Conservation and Management of Lakes Hangnzhou'90", 572-584p. 1990.

WETZEL, R.G. Limninology. Toronto, Philadelphia, England: W.B. Saunders Company, 1975. $743 \mathrm{p}$. 
WETZEL, R.G. Limnologia. Lisboa: Fundação Calouste Gulbekian, 1993, 1110 p.

ZANATA, L.H. Heterogeneidade ambiental do Reservatório de Salto Grande (Americana,SP) com ênfase na distribuição das populações de Cladocera. 1999. 218 f. Dissertação (Mestrado em Ciências Ambientais) - Centro de Recursos Hidráulicos e Ecologia Aplicada, Escola de Engenharia de São Carlos, Universidade de São Paulo, São Carlos, 1999. 